\title{
Cytokine profile and clinical correlates in HIV-exposed infants with severe (hypoxic) pneumonia
}

R J Green, ${ }^{1}$ PhD, DSc; A Terblanche, ${ }^{1}$ FCPaed (SA), Cert Gastroenterol (SA)(Paed); P Becker, ${ }^{2}$ PhD; P Rheeder, ${ }^{3}$ PhD, MMed, FCP (SA); D F Wittenberg, ${ }^{1} \mathrm{MD}$; R Anderson, ${ }^{4} \mathrm{PhD}$; R Masekela, ${ }^{1} \mathrm{PhD}$

\author{
${ }^{1}$ Department of Paediatrics and Child Health, School of Medicine, Faculty of Health Sciences, University of Pretoria, South Africa \\ ${ }^{2}$ Department of Biostatistics, Medical Research Council of South Africa, Pretoria, South Africa \\ ${ }^{3}$ Division of Clinical Epidemiology, School of Health Systems and Public Health, Faculty of Health Sciences, University of Pretoria, South Africa \\ ${ }^{4}$ Medical Research Council Unit for Inflammation and Immunity, Department of Immunology, School of Medicine, Faculty of Health Sciences, University of \\ Pretoria and Tshwane Academic Division of National Health Laboratory Service, Pretoria, South Africa
}

Corresponding author: RJ Green (robin.green@up.ac.za)

Background. Severe pneumonia in infants who are HIV-infected is a common problem in many parts of the developing world, especially sub-Saharan Africa. What has been missing from previous studies of severe pneumonia in HIV-infected infants, however, is a description of the host inflammatory response and cytokine/chemokine profile that accompanies this disease.

Objective. To describe the cytokine profiles associated with severe hypoxic pneumonia in HIV-infected and -exposed infants.

Methods. In a cohort of HIV-exposed children diagnosed clinically with severe hypoxic pneumonia, paired serum and sputum cytokines were tested. A control group of HIV-infected children with bronchiectasis contributed matching controls.

Results. A total of 100 infants (mean age 2.8 months) with a clinical diagnosis of severe hypoxic pneumonia were included in this study. IP-10 was markedly elevated in both sputum (mean $560.77 \mathrm{pg} / \mathrm{mL}$ ) and serum (mean $9091.14 \mathrm{pg} / \mathrm{mL}$ ), while IL-10 was elevated in serum (mean $39.55 \mathrm{pg} / \mathrm{mL}$ ), with both these cytokines being significantly higher than in stable children with HIV-associated bronchiectasis.

Conclusion. This study of HIV-exposed infants with severe hypoxic pneumonia suggests that IP-10 and IL-10 are associated with hypoxic lung disease in infants. However, further investigation of this association is required.

S Afr Respir J 2016;22(1):3-6. DOI: 10.7196/SARJ.2016.v22i1.60

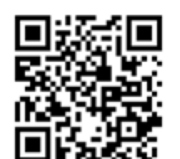

Severe pneumonia in infants who are HIV-infected is a common problem in many parts of the developing world, especially sub-Saharan Africa. It has emerged that the condition of severe hypoxic pneumonia in early infancy is a disease of many causes, most occurring together in the individual patient. ${ }^{[1-3]} \mathrm{A}$ frequent cause of severe pneumonia in infants is Pneumocystis jiroveci. This condition is usually diagnosed clinically and managed as pneumocystis pneumonia (PCP) in the regions of the world where HIV-infected children live. Today it has become possible to make a microbiological diagnosis of $P$. jiroveci based on polymerase chain reaction (PCR) testing of airway secretions. However, in the developing world such testing is largely unavailable and the clinical condition still poses an enormous problem.

$P$. jiroveci is a fungal organism that has a predilection for the immune-compromised host and is a common pathogen in HIVinfected infants. The term PCP was retained after Pneumocystis carinii was taxonomically renamed jiroveci. ${ }^{[4]}$ Since the earliest reports of HIV infection, PCP has been recognised as a severe form of acute pneumonia. The disease may occur at any age but is particularly common in early infancy. ${ }^{[5]}$ PCP is recognised clinically by a distinct set of common criteria: hypoxic pneumonia, few pulmonary crackles, an interstitial appearance on chest radiographs and an elevated lactate dehydrogenase $(>500 \mathrm{U} / \mathrm{L})$. $^{[6,7]}$ The case fatality rate from PCP is $100 \%$ if not treated with trimethoprim-sulphamethoxazole (TMP-SMX). ${ }^{[8]}$
However, where TMP-SMX prophylaxis is employed alone, mortality is not significantly reduced. ${ }^{[9]}$ Because the disease often causes severe hypoxia, these children would benefit from paediatric intensive care admission. Admitting infants with PCP to an intensive care unit, in a resource-limited setting, has created a number of ethical dilemmas for pediatricians including the historically poor outcome for these patients and the pressure on scarce resources. ${ }^{[10]}$

Cytomegalovirus (CMV) is now recognised as an important copathogen of severe pneumonia in infants and may be the organism driving mortality in this form of pneumonia. ${ }^{[1-3]}$ Treatment of this form of severe pneumonia with a combination of TMP-SMX and antiviral agents has had mixed success. ${ }^{[1-3]}$ Some studies report improved survival with use of the antiviral agent ganciclovir. ${ }^{[2,3]}$ Despite the presence of $P$. jiroveci and CMV a number of other pathogens also cause and contribute to severe hypoxic pneumonia in infants. What has been missing from previous studies of severe pneumonia in HIV-infected infants, however, is a description of the host inflammatory response and cytokine/chemokine profile that accompanies this disease. It is hoped that a better understanding of the host response and associated clinical correlates may aid in seeking better therapeutic options for these very ill children who frequently die.

The objective of this study was to document the cytokine/ chemokine profile of a group of young infants with all-cause, severe hypoxic pneumonia. 


\section{Methods}

As part of a double-blind randomised controlled trial to assess the value of systemic steroids, conducted among infants $1<18$ months of age admitted with severe hypoxic pneumonia at Pretoria Academic, Kalafong and Witbank hospitals, paired sputum and serum samples were collected for cytokine analysis. The only criterion was infants with hypoxic pneumonia. Patients were enrolled according to study protocol by the admitting doctor.

A clinical diagnosis of severe hypoxic pneumonia was made in patients with the following features:

- cough

- tachypnoea

- hypoxia (peripheral oxygen saturation $<90 \%$ in room air) out of proportion to the clinical findings on auscultation

- positive HIV-1 enzyme-linked immunosorbent assay test (ELISA) (HIV-exposed).

Ethical approval was obtained from the Research Ethics committee of the University of Pretoria, Faculty of Health Sciences (Protocol number 80/2004).

The parent(s) or guardian gave informed written consent for participation in the study, as well as for HIV testing.

Patients received either prednisone $2 \mathrm{mg} / \mathrm{kg}$ /day or placebo for 7 days. Standard antibiotic regimens including co-trimoxazole were carried out in accordance with usual practice.

The following baseline investigations were performed on admission:

- chest X-ray (CXR)

- full blood count, differential count and platelets, C-reactive protein (CRP), lactate dehydrogenase (LDH), total protein and albumin, aspartate aminotransferase (AST) and alanine aminotransferase (ALT), CD4 count, blood culture and HIV ELISA

- nasopharyngeal aspirates for respiratory viruses including CMV and PCP immunofluorescence were collected. Secretions were also tested for bacterial and tuberculosis (TB) culture.

Daily monitoring included clinical examination, recording of temperatures, oxygen saturation and oxygen requirement, and development of new features. The number of days to achieve mean oxygen saturation $>90 \%$ in room air was recorded using standard pulse oximetry.

The primary study endpoint was in-hospital survival. Secondary outcome was time from admission to the first day of mean oxygen saturation $>90 \%$ in room air.

Serum and sputum cytokines (interleukin-1beta (IL-1 $\beta$ ), interleukin-2 (IL-2), interleukin-4 (IL-4), interleukin-10 (IL-10), interleukin-12 (IL-12), interleukin-13 (IL-13), tumour necrosis factor alpha (TNF- $\alpha$ ) and interferon gamma-inducible protein-10 (IP-10)) were measured, on admission, using the Bio-Plex suspension bead array system (Bio-Rad Laboratories Inc., USA) which utilises luminex Xmap multiplex technology to enable simultaneous detection and quantitation of multiple different analytes in a single sample. A group of children with HIV-associated bronchiectasis provided serum and sputum cytokine samples and these were used as control samples since this is another disease entity where HIV infection is present.

Data analysis

Statistical analysis was performed using Stata Release 11.0 (Statacorp LP, USA). Descriptive statistics were used to describe mean/median and standard deviation (SD) of clinical, laboratory and cytokine variables. The Fisher exact test was used for categorical variables and the Mann-Whitney $U$-test for non-parametric variables. Due to the skewed distribution of the cytokine values in both groups, the groups were compared on the logarithmic scale using the Student's $t$-test. If the assumptions for the $t$-test were not met, Wilcoxon's rank sum test was applied. The geometric mean and its $95 \%$ confidence interval (CI) was reported as summary statistics again because of 'skewed data'. Before transformation to the logarithmic scale 1 was added to the observed cytokine value so as not to lose the zero values that were observed. In reporting the summary statistics the adjustment was corrected. Statistical testing was at $p<0.05$ level of significance.

\section{Results}

A total of 100 patients with a clinical diagnosis of severe hypoxic pneumonia were included in this study. There were 31 control patients (mean age 8 years) with HIV-associated bronchiectasis. The outcome of patients who received steroids compared with those who did not has been reported previously. ${ }^{[4]}$

The mean (range) age of this group of infants admitted to hospital with pneumonia is $2.8(1-12)$ months. With regard to the clinical presentation and laboratory findings of infants with pneumonia the major findings are reflected in Table 1.

Table 1. Clinical and laboratory parameters of HIV-exposed infants admitted with severe pneumonia

\begin{tabular}{llll}
\hline Variable & Mean & Range & SD \\
\hline Cough duration (days) & 8.7 & $0-60$ & 10.23 \\
Oxygen saturation $(\%)$ & 70.9 & $20-92$ & 14.52 \\
Length $(\mathrm{cm})$ & 56.3 & $43-72$ & 5.09 \\
Weight $(\mathrm{kg})$ & 4.80 & $2.7-8.5$ & 1.10 \\
Axillary temperature $\left({ }^{\circ} \mathrm{C}\right)$ & 37.4 & $36-40$ & 0.957 \\
$\mathrm{CD} 4 \%$ of total lymphocytes & 18.7 & $0.19-64$ & 12.43 \\
$\mathrm{CD} 4$ absolute $($ cells/mL) & 979.5 & $20-5247$ & 908.75 \\
$\mathrm{CRP}(\mu \mathrm{g} / \mathrm{mL})$ & 17.8 & $1-602$ & 61.82 \\
$\mathrm{LDH}(\mathrm{IU} / \mathrm{L})$ & 916.1 & $329-6249$ & 671.86 \\
& & &
\end{tabular}

The clinical chest findings in this cohort of infants with pneumonia were tachypnoea in $100(100 \%)$, respiratory recessions in 100 (100\%), subcostal recession in 94 (94\%), absence of pulmonary crackles in 71 (71\%), clinical hyperinflation in $22(22 \%)$ and wheezing in $1(1 \%)$.

The radiological findings in this cohort of infants with pneumonia were pulmonary infiltrates in $85(85 \%)$, interstitial pattern in $86(86 \%)$ and lymphadenopathy in the hilar region in 25 (25\%).

The identified pathogens were $P$. jiroveci, $\mathrm{CMV}$, respiratory sunctial virus (RSV), adenovirus, parainfluenza virus and influenza virus in 5 , 2, 8, 1, 0 and 2 infants, respectively. Bacterial pathogens and TB were not identified in any infants.

The mean (range, SD) for the measured cytokines in sputum were IL-10: 4.01 (0 - 32.68, 5.84), IL-1 $\beta$ : 278.94 (0.1 - 1 902.14, 482.34), IL-2: 13.01 (0 - 199.33, 30.19), IL-4: 1.32 (0 - 20.76, 3.16), IL-12: 7.60 (0.19 - 5 054, 7.31), IL-13: 7.13 (0 - 60.19, 8.71), IP-10: 560.77 (0 - 6975.45 , 1 024.43), TNFa: 29.44 (0 - 663.02, 89.28). 
The mean (range, SD) for the measured cytokines in serum were IL-10: 39.55 (3.15 - 308.480, 47.12), IL-1 $\beta: 25.32$ (0 - 743.5, 98.91), IL-2: 146.24 (0 - 1 070.04, 259.83), IL-4: 1.58 (0 - 15.83, 3.71), IL-12: 39.75 (0 1 112.57, 39.75), IL-13: 5.14 (0 - 64.85, 12.51), IP-10: 9091.14 (0 - 78 172.52, 11 381.98), TNFa: 104.06 (0 - 1 201.12, 213.47).

For the four cytokines that appeared to be consistently elevated in either sputum or serum in infants with severe pneumonia, namely IL10, IL-Iß, IP-10 and TNFa, comparison with children with HIV-associated bronchiectasis (mean age 8 years) is reflected in Table 2.

\section{Discussion}

The age of this cohort of infants with severe hypoxic pneumonia is in keeping with previous publications suggesting that severe hypoxic pneumonia occurs in very young infants (age 2 - 3 months). ${ }^{[9]}$ This fact is of critical importance to preventive strategies and policies. Only an effective prevention of mother-to-child (PMTC) programme will solve this problem. Early HIV detection in childhood and vaccine programmes are not a solution, as the disease occurs so early in life.

The clinical findings support previous research indicating that this form of pneumonia in young HIV-exposed children is associated with severe hypoxia and relatively few pulmonary adventitious sounds. ${ }^{[1]} \mathrm{LDH}$ has been suggested as a diagnostic test for PCP, with levels $>500$ IU/L taken as positive evidence. ${ }^{[6]}$ Whilst not all the infants in this study had a LDH >500 IU/L, most did. This result does not support a specific aetiological agent in the cause of this form of pneumonia but rather supports the severe nature of the pulmonary insult. The clinical profile of this disease is distinct in the nature of its severity.

The radiological findings, whilst most usually reflecting an interstitial (or alveolar) pattern, are not universally so. This too has been previously documented. ${ }^{[12]}$

The lack of identifiable organisms causing this disease probably reflects the insensitive nature of the testing methods. This is a weakness of the study, and this study would have been significantly strengthened by newer PCR tests, which unfortunately were not available at the time of the study. This lack of a definitive causative agent responsible for the pneumonia is, however, not a detraction from the major aim of the study, that being to document the cytokine profile of

\begin{tabular}{|c|c|c|c|}
\hline Cytokine / Group & Geometric mean & 95\% CI & $p$-value ${ }^{*}$ \\
\hline \multicolumn{4}{|l|}{ Sputum IL-10 } \\
\hline Severe pneumonia & 1.93 & $1.30 ; 2.74$ & \\
\hline Bronchiectasis & 0.78 & $0.51 ; 1.10$ & 0.0196 \\
\hline \multicolumn{4}{|l|}{ Sputum IL-1 $\beta$} \\
\hline Severe pneumonia & 40.12 & $22.63 ; 70.56$ & \\
\hline Bronchiectasis & 692.07 & $372.36 ; 1285.54$ & $<0.001$ \\
\hline \multicolumn{4}{|l|}{ Sputum IP-10 } \\
\hline Severe pneumonia & 154.33 & $90.24 ; 263.45$ & \\
\hline Bronchiectasis & 12.76 & $6.09 ; 25.71$ & $<0.001$ \\
\hline \multicolumn{4}{|l|}{ Sputum TNFa } \\
\hline Severe pneumonia & 5.30 & $3.33 ; 8.16$ & \\
\hline Bronchiectasis & 11.57 & $7.74 ; 179.89$ & 0.0402 \\
\hline \multicolumn{4}{|l|}{ Serum IL-10 } \\
\hline Severe pneumonia & 24.86 & $19.78 ; 31.19$ & \\
\hline Bronchiectasis & 4.48 & $3.54 ; 5.63$ & $<0.001$ \\
\hline \multicolumn{4}{|l|}{ Serum IL-1 $\beta$} \\
\hline Severe pneumonia & 2.97 & $1.69 ; 4.86$ & \\
\hline Bronchiectasis & 4.38 & $2.17 ; 8.15$ & 0.3815 \\
\hline \multicolumn{4}{|l|}{ Serum IP-10 } \\
\hline Severe pneumonia & 5372.59 & $3877.70 ; 7443.63$ & \\
\hline Bronchiectasis & 4144.67 & $292.90 ; 5856.94$ & 0.0078 \\
\hline \multicolumn{4}{|l|}{ Serum TNFa } \\
\hline Severe pneumonia & 14.39 & $8.06 ; 25.15$ & \\
\hline Bronchiectasis & 5.89 & $2.05 ; 4.56$ & 0.1009 \\
\hline
\end{tabular}

HIV-exposed infants with severe hypoxic pneumonia.

Normal values for cytokines and chemokines in health and disease are not readily available, and this is a limitation of this study. There is evidence that in healthy children and infants the cytokines measured in this study should be zero or at most very low values. ${ }^{[13]}$ The lack of a definitive control group of normal children against which the cytokines are measured is a weakness of this study. However, in order to nullify the effect of HIV infection per se on the cytokine changes, it was decided to use a group of children with another form of HIVrelated pathology, but one in which acute infection was not present. Hence the value of children with HIV-associated bronchiectasis as a control group. Clearly this is not an ideal comparator group because of differences in age at presentation and degrees of disease severity.
This limitation is noted. Subclinical infection is, however, a possibility and might influence the results. The cytokine results suggest that the major cytokines associated with severe hypoxic pneumonia in very young, HIV-infected, infants are IL-10 and IP-10. Neither cytokine was significantly elevated in the control group, suggesting that the elevated values are due to the effect of acute and severe pneumonia in infants.

IL-10 is a cytokine that has important anti-inflammatory properties. ${ }^{[14]}$ Coded for by the IL-10 gene, this cytokine is produced mainly by monocytes and to some extent by lymphocytes. ${ }^{[15]}$ It has a major function in down-regulating the expression of Th1 cytokines. ${ }^{[14]}$ There is a paucity of data on the presence of IL-10 in paediatric lung disease, especially pneumonia. However, in a study of children with severe sepsis or pneumonia, IL-10 was found to be elevated in the serum 
of the children with severe sepsis but not pneumonia. ${ }^{[16]}$ In other paediatric pulmonary conditions there is evidence that IL-10 is elevated in RSV infection, ${ }^{[17]}$ bronchopulmonary dysplasia ${ }^{[18]}$ and Mycoplasma pneumoniae pneumonia. ${ }^{[1]]}$ An adult study of patients with communityacquired pneumonia suggests that IL-10 functions as an acute-phase reactant. ${ }^{[20]}$ The finding of elevated sputum and serum IL-10 in the current study of infants with severe pneumonia is a new finding and suggests that the anti-inflammatory defences of the HIV-infected infant are mobilised early after the onset of severe pneumonic pathology. It is also possible that this cytokine may function in a pro-inflammatory way in this condition.

IP-10 is a chemokine that is secreted by several cell types, including monocytes, endothelial cells and fibroblasts, in response to INF-y. ${ }^{[21]}$ It functions as a chemoattractant for macrophages, T-cells, NK-cells and dendritic cells and also has a number of newly identified functions including promotion of T-cell adhesion to endothelial cells, antitumour activity and inhibition of angiogenesis. ${ }^{[22,23]}$ It has not previously been associated with a specific form of pneumonia in children. High levels of this chemokine have been shown to be associated with a poorer outcome in HIV-infected individuals with hepatitis C viral (HCV) co-infection. ${ }^{[4]} \mathrm{IP}-10$ has been documented as a better test than both interferon gamma-based QuantiFERON TB Gold assays and tuberculin skin tests for diagnosing TB in HIV-infected individuals. ${ }^{[25]} \mathrm{HCV}$ was not measured in our study but all children had normal levels of liver enzymes. TB was not seen in our children. Elevation of this chemokine in infants with severe pneumonia may reflect significant stimulation of monocytes, in keeping with the elevated values of IL-10. It may have pro- or anti-inflammatory activity in this disease state. These functions, however, require more extensive study.

Previous studies have attempted to characterise the cytokine profile of $P$. jiroveci-infected individuals. These studies suggest that the actual cause of the immunosuppression predisposing to the infection may have as much impact on the cytokine profile as the organism itself. ${ }^{[2,27]}$ This latter study suggests that $P$. jiroveci infection is associated with reduced macrophages in alveoli and elevated IL-6. However, IP-10 was not measured in that study.

IL- $1 \beta$ and TNF $\alpha$ are found to be lower in infants with severe pneumonia than the comparator group of children with bronchiectasis. The reason for this finding is unknown and should be investigated further.

\section{Study limitations}

This study was not without significant limitations. Some of these include lack of definition of severity groups within both sample populations, failure to standardise sample collection, timing to disease onset and most importantly that the age of the two sample populations are markedly different.

\section{Conclusion}

This study of HIV-exposed infants with severe hypoxic pneumonia suggests that IL-10 and IP-10 are associated with hypoxic pneumonia in infants. However, further investigation of this association is required.

\section{References}

1. Morrow BM, Hsaio NY, Zampoli M, Whitelaw A, Zar HJ. Pneumocystis pneumonia in South African children with and without human immunodeficiency virus infection in the era of highly active antiretroviral therapy. Pediatr Infect Dis J 2010;29(6):535539. [http://dx.doi.org/10.1097/INF.0b013e3181ce871e]
2. Zampoli M, Morrow B, Hsiao NY, Whitelaw A, Zar HJ. Prevalence and outcome of cytomegalovirus associated pneumonia in relation to human immunodeficiency virus infection. Pediatr Infect Dis J 2011;30(5):413-417. [http://dx.doi.org/10.1097/ INF.0b013e3182065197]

3. Goussard P, Kling S, Gie RP, et al. CMV pneumonia in HIV-infected ventilated infants. Pediatr Pulmonol 2010;45(7):650-655. [http://dx.doi.org/10.1002/ppul.21228]

4. Stringer JR, Beard CB, Miller RF, Wakefield AE. A new name (Pneumocystis jiroveci) for pneumocystis from humans. Emerg Infect Dis 2002;8(9):891-896. [http://dx.doi. org/10.3201/eid0809.020096]

5. Jeena P. The role of HIV on respiratory tract infection in sub-Saharan Africa. Int J Tuberc Lung Dis 2005;9(7):708-715.

6. Fatti GL, Zar HJ, Swingler GH. Clinical indicators of Pneumocystis jiroveci pneumonia (PCP) in South African children infected with human immunodeficiency virus. Int J Infect Dis 2006;10(4):282-285. [http://dx.doi.org/10.1016/j.ijid.2005.06.007]

7. Terblanche AJ, Green RJ, Rheerder P, Wittenberg DF. Adjunctive corticosteroid treatment of clinical Pneumocystis jiroveci pneumonia in infants less than 18 months of age - a randomized controlled trial. S Afr Med J 2008;98(4):287-290.

8. Madhi SA, Cutland C, Ismail K, O’ Reilly C, Mancha A, Klugman KP. Ineffectiveness of trimethoprim-sulfamethoxazole prophylaxis and the importance of bacterial and viral coinfections in African children with Pneumocystis carinii pneumonia. Clin Infect Dis 2002;35(9):1120-1126. [http://dx.doi.org/10.1086/343049]

9. Kitchin O, Masekela R, Becker P, Moodley T, Risenga SM, Green RJ. Outcome of HIV exposed and infected children admitted to a Pediatric Intensive Care Unit for respiratory failure. Pediatr Crit Care Med 2012;13(5):516-519. [http://dx.doi. org/10.1097/PCC.0b013e31824ea143]

10. Jeena MP, McNally LM, Stobie M, Coovadia HM, Adhikari MA, Petros AJ. Challenges in the provision of ICU services to HIV infected children in resource poor settings: A South African case study. J Med Ethics 2005;31(4):226-230. [http://dx.doi.org/10.1136/jme.2003.004010]

11. Zar HJ, Dechaboon A, Hanslo D, Apolles P, Magnus KG, Hussey G. Pneumocystis carinii pneumonia in South African children infected with human immunodeficiency virus. Pediatr Infect Dis J 2000;19(7):603-607.

12. Pitcher RD, Daya R, Beningfield SJ, Zar HJ. Chest radiographic presenting features and radiographic progression of pneumocystis pneumonia in South African children. Pediatr Pulmonol 2011;46(10):1015-1022. [http://dx.doi.org/10.1002/ppul.21465]

13. Okazaki K, Kondo M, Kato M, et al. Serum cytokine and chemokine profiles in neonates with meconium aspiration syndrome. Pediatrics 2008;121(4):748-753.

14. Said EA, Dupuy FP, Trautmann L, et al. Programmed death-1-induced interleukin-10 production by monocytes impairs CD4+ T cell activation during HIV infection. Nat Med 2010;16(4):452-459. [http://dx.doi.org/10.1038/nm.2106]

15. Eskdale J, Kube D, Tesch H, Gallagher G. Mapping the human IL10 gene and further characterization of the 5' flanking sequence. Immunogenetics 1997;46(2):120-128.

16. Chen DH, Li YM, Lan SL, et al. The level and clinical significance of Toll-like receptor 4 in children with severe sepsis. Zhongguo Wei Zhong Bing Ji Jiu Yi Xue 2011;23(8):475-477.

17. Midulla F, Tromba V, Lo Russo L, et al. Cytokines in the nasal washes of children with respiratory syncytial virus bronchiolitis. Int J Immunopath Pharmacol 2006;19(1):231-235.

18. Garingo A, Tesoriero L, Cayabyab R, et al. Constitutive IL-10 expression by lung inflammatory cells and risk for bronchopulmonary dysplasia. Pediatr Res 2007;61(2):197-202. [http://dx.doi.org/10.1203/pdr.0b013e31802d8alc]

19. Pang HX, Qiao HM, Cheng HJ, Zhang YF, Liu XJ, Li JZ. Levels of TNF- $\alpha$, IL-6 and IL-10 in bronchoalveolar fluid in children with Mycoplasma pneumoniae pneumonia. Zhongguo Dang Dai Er Ke Za Zhi 2011;13(10):808-810.

20. Endeman H, Meijvis SC, Rijkers GT, et al. Systemic cytokine response in patients with community-acquired pneumonia. Eur Respir J 2011;37(6):1431-1438.

21. Luster AD, Unkeless JC, Ravetch JV. Gamma-interferon transcriptionally regulates an earlyresponse gene containing homology to platelet proteins. Nature 1985;315(6021):672-676.

22. Dufour JH, Dxiejman M, Liu MT, Leung JH, Lane TE, Luster AD. IFN-gammainducible protein 10 (IP-10; CXCL 10)-deficient mice reveal a role for IP-10 in effector T cell generation and trafficking. J Immunol 2002;168(7):3195-3204.

23. Angiolillo AL, Sgadari C, Taub DD, et al. Human interferon-inducible protein 10 is a potent inhibitor of angiogenesis in vivo. J Exp Med 1995;182:155-162.

24. Falconer K, Askarieh G, Weis N, Hellstrand K, Alaeus A, Lagging M. IP-10 predicts the first phase decline of HCV RNA and overall viral response to therapy in patients co-infected with chronic hepatitis C virus infection and HIV. Scand J Infect Dis 2010;42:11-12.

25. Syed Ahamed Kabeer B, Sikhamani R, Raja A. Comparison of interferon gamma-inducible protein-10 and interferon gamma-based QuantiFERON TB Gold assays with tuberculin skin test in HIV-infected subjects. Diagn Microbiol Infect Dis 2011;71(3):236-243.

26. Tasaka S, Kobayashi S, Kamata H, et al. Cytokine profiles of bronchoalveolar lavage fluid in patients with pneumocystis pneumonia. Microbiol Immunol 2010;54(7):425-433.

27. Iriart X, Witkowski B, Courtais C, et al. Cellular and cytokine changes in the alveolar environment among immunocompromised patients during Pneumocystis jirovecii infection. Med Mycol 2010;48(8):1075-1087. [http://dx.doi.org/10.3109/13693786.2010.484027] 